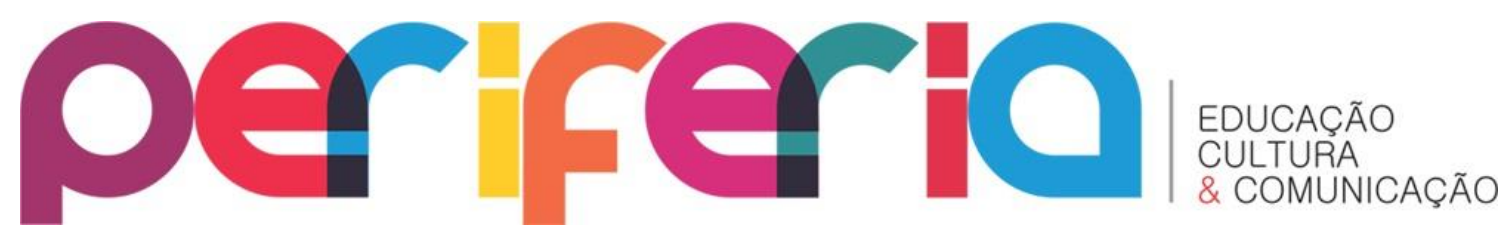

\title{
AS ESCOLAS MULTISSERIADAS COMO POSSIBILIDADE DE CONCRETIZAÇÃO DO DIREITO À EDUCAÇÃO
}

\author{
Maria Claudia Zaratini Maia ${ }^{1}$
}

\section{Resumo}

A educação é um direito assegurado amplamente pela legislação, seja em âmbito nacional e internacional, mas há dificuldades na sua concretização, especialmente para as populações historicamente excluídas deste direito, como a população do campo. Por meio deste trabalho, de revisão bibliográfica e documental, busca-se demonstrar que a educação no campo tem peculiaridades próprias que devem ser observadas na concretização do direito à educação. $\mathrm{E}$, para garantir o direito à educação desta população, como a igualdade de acesso e permanência na escola deve-se manter a escola na própria comunidade em que a criança vive, podendo, como alternativa para evitar o fechamento de escolas e o transporte das crianças, utilizar-se da organização escolar em escolas/classes multisseriadas. Há um senso comum de que a multisseriação violaria o direito à educação da criança, mas busca-se apontar, por meio deste trabalho, que atendidas as necessidades deste tipo de organização escolar, ela é, na verdade, uma alternativa pedagógica para concretizar o direito à educação da população do campo.

Palavras-chave: escola multisseriada; educação no campo; direito à educação.

\section{MULTIGRADE SCHOOL AS A POSSIBILITY OF ACHIEVING THE RIGTH DO EDUCATION}

\section{Abstract}

Education is a right widely guaranteed by legislation, both at national and international levels, but there are difficulties in achieving it, especially for populations historically excluded from this right, such as the rural population. Through this work, of bibliographic and documentary review, we seek to

\footnotetext{
1 Mestre em Sistema Constitucional de Garantia de Direitos pela ITE-Bauru e Doutora em Educação pela Universidade Federal de São Carlos - UFSCar. Advogada e Professora das Faculdades Integradas de Bauru - SP. ORCID iD: https://orcid.org/0000-0002-5086-227X E-mail: maiamariaclaudia@gmail.com
} 


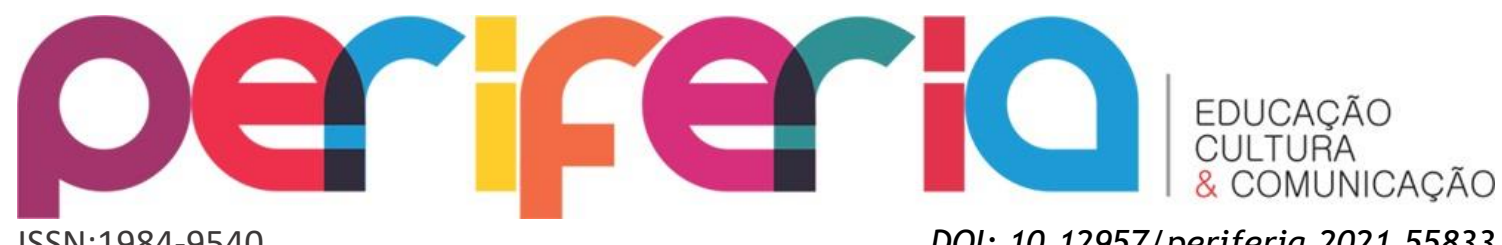

ISSN:1984-9540

DOI: $10.12957 /$ periferia.2021.55833

demonstrate that education in the countryside has its own peculiarities that must be observed in the realization of the right to education. And, in order to guarantee the right to education for this population, such as equal access and permanence at school, the school must be maintained in the community in which the child lives, and as an alternative to avoid closing schools and transporting children, use the school organization in multi-grade schools / classes. There is a common sense that the multiseries would violate the right to education of the child, but it is sought to point out, through this work, that given the needs of this type of school organization, it is, in fact, a pedagogical alternative to concretize the right to education of the rural population.

Keywords: Multigrade School; Rural Education; Rigth to education.

\section{ESCUELA MULTIGRADO COMO POSIBILIDAD DE CUMPLIR EL DERECHO A LA EDUCACIÓN}

\section{Resumen}

La educación es un derecho ampliamente garantizado por la legislación, tanto a nivel nacional como internacional, pero existen dificultades para lograrlo, especialmente para poblaciones históricamente excluidas de este derecho, como la población rural. A través de este trabajo, de revisión bibliográfica y documental, buscamos demostrar que la educación en el campo tiene peculiaridades propias que deben observarse en la realización del derecho a la educación. Y, para garantizar el derecho a la educación de esta población, como la igualdad de acceso y permanencia en la escuela, la escuela debe mantenerse en la comunidad en la que vive el niño, y como alternativa para evitar el cierre de escuelas y el transporte de niños. , utilice la organización escolar en escuelas / clases de varios grados. Existe un sentido común de que la multiserie violaría el derecho a la educación del niño, pero se busca señalar, a través de este trabajo, que dadas las necesidades de este tipo de organización escolar, es, de hecho, una alternativa pedagógica para concretar el derecho a la educación. educación de la población rural.

Palabras clave: Escuela Multigrado. Educación de Campo. Derecho a la educación. 


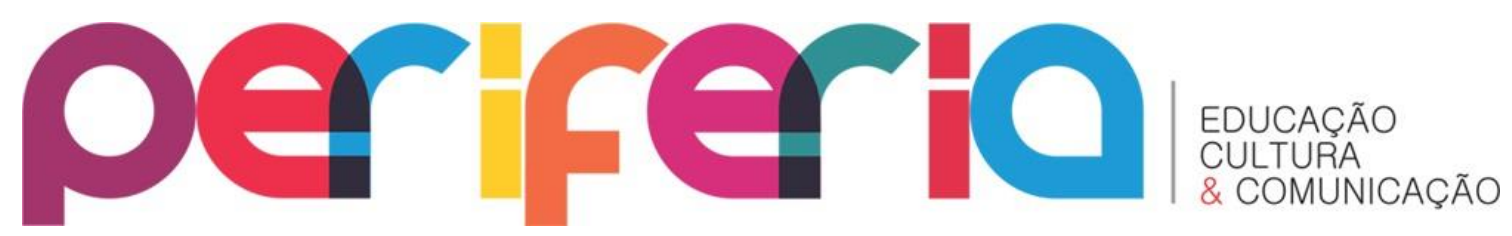

INTRODUÇÃO

A educação é um direito humano fundamental garantido na Constituição da Federal de 1988 e assegurada em documentos internacionais em que o Brasil está comprometido desde a Declaração Universal dos Direitos Humanos de 1948. Mas, a garantia do direito, apesar de importante, não significa que ele se concretize na vida da população, especialmente no caso da população brasileira que tem acesso aos direitos e à distribuição de riqueza de forma totalmente desigual.

A educação no campo também é um direito humano fundamental e ela passa a ter regulamentação específica, com essa denominação, a partir da década de 1990 e, desde então, vem sendo impulsionada e cobrada pela população do campo e pelos movimentos sociais que tiveram e têm papel importante em seu desenvolvimento, pois reivindicam uma educação pública, gratuita e de qualidade socialmente referenciada.

Um dos requisitos para concretizar o direito à educação da população do campo é que a escola esteja próxima à criança e uma das soluções encontradas para evitar a nucleação e fechamento de escolas do campo, com o transporte das crianças por grandes distâncias, é a organização do ensino em salas multisseriadas, mormente na educação infantil e primeiros anos do ensino fundamental.

Todavia, há um senso comum de que tal forma de organizar o ensino compromete a sua qualidade, fazendo com que fique aquém do ensino organizado em classes seriadas, o que inclusive já gerou várias intervenções do Ministério Público em alguns estados brasileiros no sentido de fechar tais salas e efetuar o transporte das crianças para outra escola.

O trabalho utilizou a metodologia de revisão bibliográfica e documental, a partir de autores que trabalham a educação no campo, o direito à educação, bem como legislações e instrumentos normativos que regulamentam a matéria, e busca responder se as salas multisseriadas utilizadas para evitar a nucleação de estudantes da educação infantil e primeiros anos do ensino fundamental 


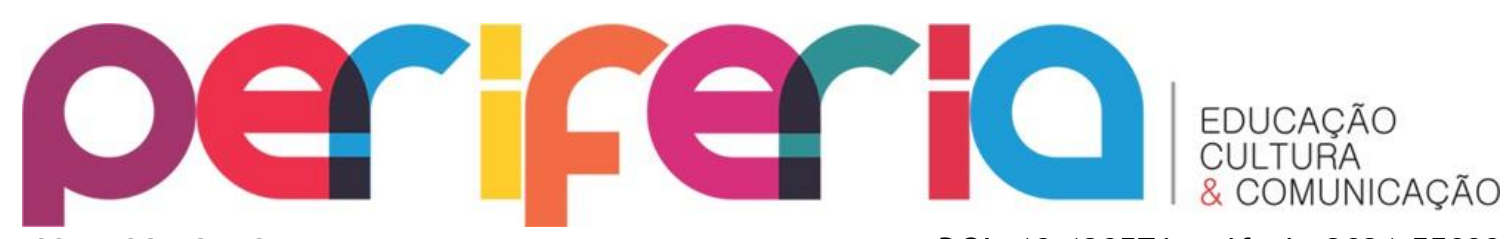

ISSN:1984-9540

DOI: $10.12957 /$ periferia.2021.55833

podem ser uma forma de concretizar o direito à educação da população do campo.

\section{Direito Humano Fundamental à Educação}

Defende-se que a educação para a população do campo, ocorra "no campo", ou seja, que a escola tenha que chegar até as comunidades rurais e atender às crianças que ali residam e que proporcionem, a essas crianças, o acesso ao conhecimento historicamente sistematizado por meio da escola pública, gratuita e de qualidade socialmente referenciada.

O direito à educação está amplamente assegurado pela legislação brasileira, desde a Constituição Federal de 1988 que prevê que a educação é direito de todos e dever do Estado até legislações infraconstitucionais e atos normativos do Ministério da Educação. E, para além da legislação interna, o Brasil se compromete a garantir direito à educação desde a assinatura da Declaração Universal dos Direitos Humanos, de 1948 o Pacto de Direitos Econômicos Sociais e Culturais, de 1966, bem como outros documentos internacionais específicos que tratam do direito à educação.

Por isso o Estado brasileiro deve assegurar a todos o acesso $\mathrm{e}$ permanência, em igualdade de condições, à educação básica, obrigatória, gratuita, de qualidade, desde a educação infantil até o ensino médio e ainda o acesso ao ensino superior, conforme artigos 205 a 208 da Constituição Federal (BRASIL, 1988).

É certo que ter um direito garantido por lei não significa sua concretização, já que os direitos são relações sociais, são processos e sua garantia é importante, mas dependem de luta para sua concretização, especialmente em sociedades abissalmente desiguais, como a brasileira.

Cury (2002) aponta esse caráter contraditório entre o que está legislado e o que efetivamente se concretiza como direito.

É por essas razões que a importância da lei não é identificada e reconhecida como um instrumento linear ou mecânico de 


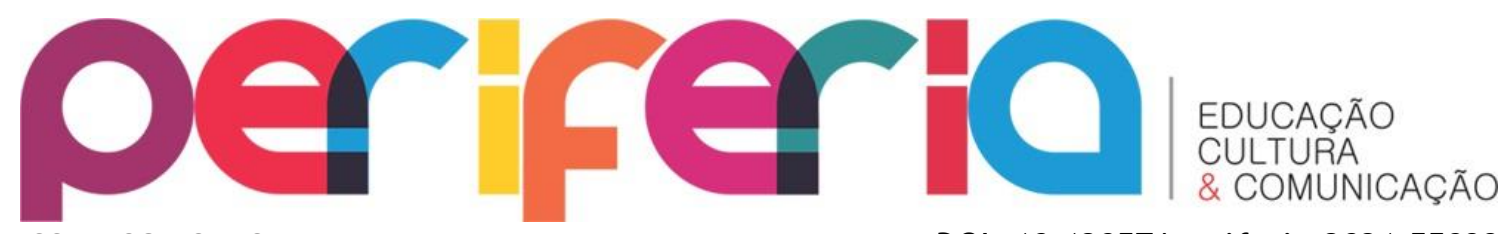

ISSN:1984-9540

realização de direitos sociais. Ela acompanha o desenvolvimento contextuado da cidadania em todos os países. A sua importância nasce do caráter contraditório que a acompanha: nela sempre reside uma dimensão de luta. Luta por inscrições mais democráticas, por efetivações mais realistas, contra descaracterizações mutiladoras, por sonhos de justiça. Todo o avanço da educação escolar além do ensino primário foi fruto de lutas conduzidas por uma concepção democrática da sociedade em que se postula ou a igualdade de oportunidades ou mesmo a igualdade de condições sociais (CURY, 2002, p. 247).

A importância da educação como direito, principalmente a educação básica é que ela é capaz de possibilitar o desenvolvimento racional do ser humano, para que possa compreender, interagir, integrar e até modificar o mundo em que vive, daí a necessidade desse direito ser assegurado pelo Estado, de forma gratuita, obrigatória e universal. A educação é que possibilita o acesso a outros direitos.

A concretização desse direito, em uma sociedade desigual passa por tensões entre interesses de classes e também pela luta de grupos historicamente excluídos, como ocorre com a população do campo. E, ainda, passa pela concretização da igualdade, ou seja, assegurar as especificidades e características da população do campo, para concretizar seu direito à educação.

Por isso, os Estados democráticos de direito zelam em assinalar as discriminações que devem ser sempre proibidas: origem, raça, sexo, religião, cor, crença. Ao mesmo tempo, seria absurdo pensar um igualitarismo, uma igualdade absoluta, de modo a impor uniformemente as leis sobre todos os sujeitos e em todas as situações. Um tratamento diferenciado só se justifica perante uma situação objetiva e racional e cuja aplicação considere o contexto mais amplo. A diferença de tratamento deve estar relacionada com o objeto e com a finalidade da lei e ser suficientemente clara e lógica para a justificar (CURY, 2002 p. 255/256).

O direito à educação como um todo e, especificamente o direito à educação no campo, foi historicamente deixado em segundo plano no Brasil, e nesse cenário de negação de direitos é que a classe trabalhadora do campo 


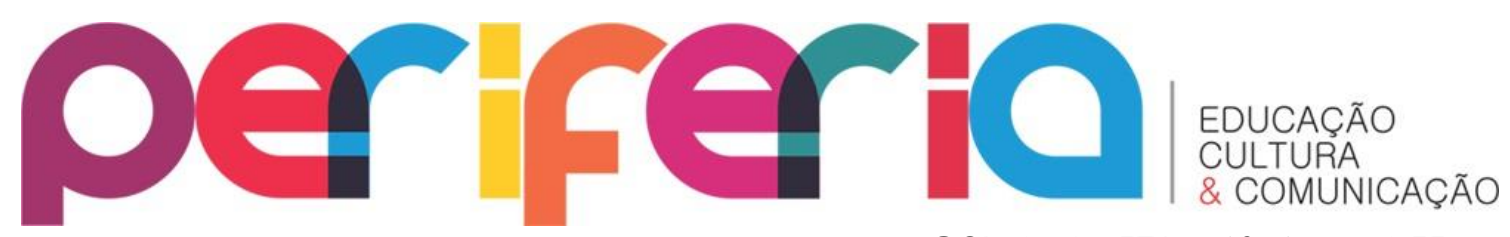

ISSN:1984-9540

DOI: $10.12957 /$ periferia.2021.55833

organizada em movimentos sociais e sindicais passou a reivindicar a escolarização das crianças e de jovens e adultos que produzem suas condições materiais de existência a partir do trabalho no meio rural (MAIA, 2019).

E, no final da década de 1990 que se organiza a luta pela educação do campo e a reivindicação de políticas públicas específicas para efetivação do direito à educação para esta população, com o I Encontro Nacional de Educadores da Reforma Agrária (Enera), realizado em julho de 1997 em parceria com a Universidade de Brasília (UnB) o Fundo das Nações Unidas para a Infância (Unicef) a Organização das Nações Unidas para a Educação, a Ciência e a Cultura (Unesco) e a Conferência Nacional de Bispos (CNBB) e Movimento dos Trabalhadores Rurais sem Terra (MST) representado pelo seu setor de educação. Em seguida a Portaria 10 do Ministério Extraordinário de Política Fundiária, que cria o PRONERA - Programa Nacional de Educação na Reforma Agrária, política pública de educação do campo desenvolvida nas áreas de Reforma Agrária e executada pelo Ministério do Desenvolvimento Agrária, por meio do Instituto Nacional de Colonização e Reforma Agrária - INCRA (BEZERRA NETO; SANTOS; BEZERRA, 2016).

No ano seguinte, entre os dias 27 e 31 de julho de 1998 ocorreu a I Conferência Nacional por uma Educação Básica do Campo (Cnec) reafirmando a necessidade de inclusão e manutenção da educação do campo na agenda política brasileira (BEZERRA NETO; SANTOS, 2016) e, em seguida foram editados vários atos normativos do Ministério da Educação para regulamentar a educação básica do campo. Por fim, a política pública de educação do campo é efetivamente regulamentada pelo Decreto n. 7.352, de 4 de novembro de 2010, que institucionalizou a política pública (BRASIL, 2010).

Assim, na medida em que a população do campo passa a se enxergar como sujeito de direito, como titular do direito à educação e com possibilidade de acesso ao conhecimento, é que esse direito passa a ser exigido e há uma regulamentação própria, no sentido de exigir que se concretize esse direito.

Até então, tal fato não havia ocorrido na história brasileira, como descreve Molina: 


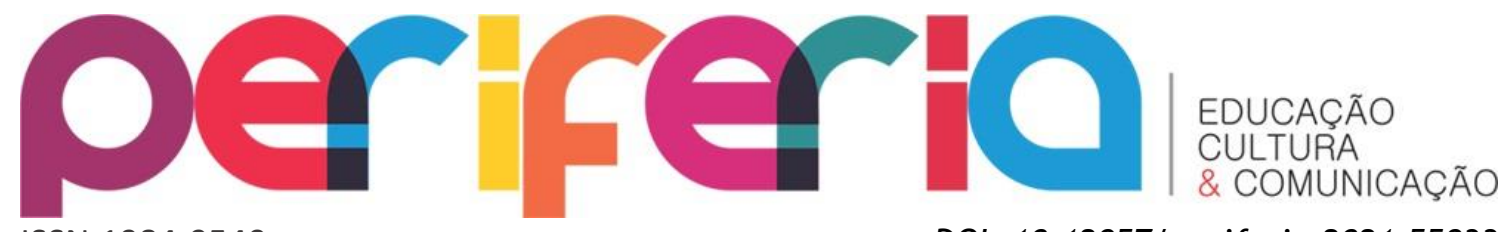

DOI: $10.12957 /$ periferia.2021.55833

Neste ponto, está uma das principais forças que a Educação do Campo acumulou nos últimos doze anos: a luta dos Movimentos Sociais e sindicais do campo para conquistar os programas existentes fez também avançar o imaginário social dos trabalhadores rurais sobre a importância do acesso ao conhecimento e, principalmente, contribuiu para que eles próprios se conscientizassem de que são titulares do direito à educação (MOLINA, 2010, p. 42).

A importância do reconhecimento da educação, como direito subjetivo, também da classe trabalhadora do campo é que amplia e possibilita a regulamentação própria e o respeito às peculiaridades próprias de quem vive em áreas rurais. Se não basta apenas prever o direito para efetivá-lo é certo que sem a previsão legal, ele certamente não se concretizará:

\begin{abstract}
A declaração e a garantia de um direito tornam-se imprescindíveis no caso de países, como o Brasil, com forte tradição elitista e que tradicionalmente reservam apenas às camadas privilegiadas o acesso a este bem social. Por isso, declarar e assegurar é mais do que uma proclamação solene. Declarar é retirar do esquecimento e proclamar aos que não sabem, ou esqueceram, que eles continuam a ser portadores de um direito importante. Disso resulta a necessária cobrança deste direito quando ele não é respeitado. (CURY, 2002, p. 259).
\end{abstract}

Além de que, a previsão legal da educação como direito, faz nascer o direito público subjetivo ${ }^{2}$, ou seja, a possibilidade que se exija seu cumprimento pelo Estado brasileiro, seja pela via judicial, política ou administrativa (MAIA, 2011 e TAGLIAVINI; TAGLIAVINI; MAIA, 2015).

Portanto, o direito assegurado implica em dever do Estado:

Este jogo entre direito e dever implica aos interessados, quando na falta deste atendimento, o acionar de instrumentos jurídicos e processuais capazes de fazer respeitar um direito claramente protegido. Nesse sentido, a Constituição aciona a própria sociedade civil como espaço consciente de poder e de controle

2 Constituição Federal de 1988: Art. 208. § $1^{\circ} \mathrm{O}$ acesso ao ensino obrigatório e gratuito é direito público subjetivo.

LDB: Art. $5^{\circ} \mathrm{O}$ acesso à educação básica obrigatória é direito público subjetivo, podendo qualquer cidadão, grupo de cidadãos, associação comunitária, organização sindical, entidade de classe ou outra legalmente constituída e, ainda, o Ministério Público, acionar o poder público para exigi-lo. 


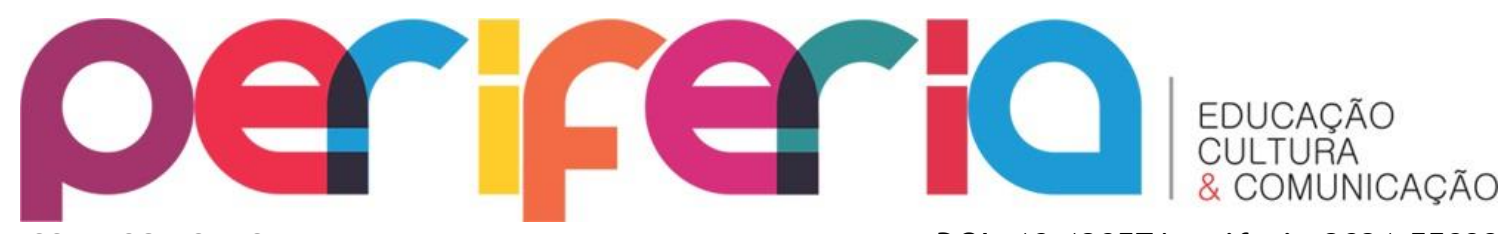

ISSN:1984-9540

DOI: $10.12957 /$ periferia.2021.55833

democrático do próprio Estado, a fim de que nenhum cidadão fique sem o benefício da educação escolar. (CURY, 2002, p. 260)

Nesse sentido, este direito não nasce do consenso, mas de resistências e mobilizações que resultaram na regulamentação da educação no campo, buscando garantir o direito subjetivo de educação pública de qualidade e socialmente referenciada à população do campo, que é composta pelos:

[...] agricultores familiares, os extrativistas, os pescadores artesanais, os ribeirinhos, os assentados e acampados da reforma agrária, os trabalhadores assalariados rurais, os quilombolas, os caiçaras, os povos da floresta, os caboclos e outros que produzam suas condições materiais de existência a partir do trabalho no meio rural (BRASIL, 2010)

E, o desafio de assegurar o direito à educação para a população do campo é ainda maior porque:

[...] as suas diversidades e suas especificidades formam, representam, constituem as bases materiais da ação coletiva para a transposição histórica do descaso, da precarização e da marginalização da escola rural, bem como para a elaboração de políticas públicas de educação que levem em conta a existência, a trajetória, a história, as dinâmicas e as complexas realidades dos sujeitos que vivem e trabalham no campo. (BEZERRA NETO; SANTOS; BEZERRA, 2016, p. 91).

Desta forma, o direito à educação no campo está, assim como os demais direitos, em constante construção de acordo com as exigências, necessidades e especificidades da população do campo, que historicamente esteve em condição de maior vulnerabilidade social que a população das cidades. 


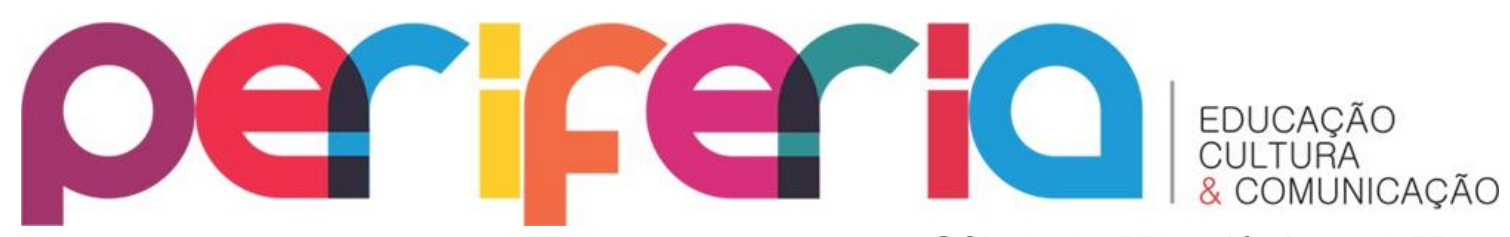

3. Garantia de Educação às Crianças na Educação Infantil e Ensino Fundamental no Campo.

As crianças são seres humanos em desenvolvimento e todas, sejam elas moradoras da cidade ou do campo, têm direito à educação pública, gratuita e de qualidade socialmente referenciada, ou seja, direito a oportunidade de ter acesso ao conhecimento historicamente sistematizado pela sociedade.

O Estatuto da Criança e do Adolescente, Lei n 13.069 de 13 de julho de 1990, foi criado por um compromisso constitucional com a garantia de direitos às crianças e adolescentes brasileiros e sua proteção integral. Trata dos direitos fundamentais das crianças e adolescentes, em especial, o direito à vida, à saúde, liberdade, respeito e dignidade; direito à convivência familiar e comunitária e educação, cultura, esporte e lazer, dentre outros direitos.

Ao tratar do direito à educação da criança e adolescente o Estatuto estabelece regras que reiteram as garantias constitucionais quanto ao direito à educação ao assegurar aos estudantes "a igualdade de condições de acesso e permanência na escola" e vai além ao garantir o "acesso à escola pública e gratuita mais próxima de sua residência", conforme descrito no artigo 53 do Estatuto, que reproduzimos abaixo:

Art. 53. A criança e o adolescente têm direito à educação, visando ao pleno desenvolvimento de sua pessoa, preparo para o exercício da cidadania e qualificação para o trabalho, assegurando-se-lhes:

I - igualdade de condições para o acesso e permanência na escola;

II - direito de ser respeitado por seus educadores;

III - direito de contestar critérios avaliativos, podendo recorrer às instâncias escolares superiores;

IV - direito de organização e participação em entidades estudantis;

V - acesso à escola pública e gratuita, próxima de sua residência, garantindo-se vagas no mesmo estabelecimento a 


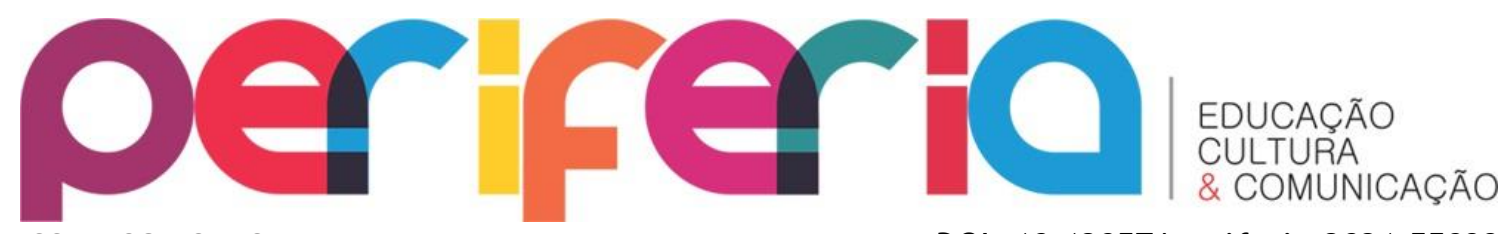

DOI: $10.12957 /$ periferia.2021.55833

irmãos que frequentem a mesma etapa ou ciclo de ensino da educação básica. (Redação dada pela Lei nº 13.845, de 2019)

Parágrafo único. É direito dos pais ou responsáveis ter ciência do processo pedagógico, bem como participar da definição das propostas educacionais (BRASIL, 1990).

Assim, a garantia legal, como direito, de igualdade de acesso e permanência na escola e também a garantia de ter acesso à escola pública e gratuita próxima de sua residência, asseguram que as crianças, por meio de seus representantes legais, possam exigir a existência da escola do campo próxima à residência, bem como se mobilizar para evitar seu fechamento.

A Lei de Diretrizes e Bases da Educação Nacional, ou Lei n.9.394 de 20 de dezembro de 1996 foi a segunda lei brasileira a estabelecer as diretrizes da educação em âmbito nacional, tratou também da educação no campo, que denomina de educação rural, no capítulo que da Educação Básica.

Ao prever, no artigo 23, que a forma de organização da educação básica em séries anuais, períodos semestrais, ciclos e alternância regular de períodos de estudos e ainda, de grupos não seriados, contemplou duas formas de organização usuais na educação no campo, como a pedagogia da alternância e o ensino em classes multisseriadas. Abaixo a íntegra do artigo 23:

Art. 23. A educação básica poderá organizar-se em séries anuais, períodos semestrais, ciclos, alternância regular de períodos de estudos, grupos não-seriados, com base na idade, na competência e em outros critérios, ou por forma diversa de organização, sempre que o interesse do processo de aprendizagem assim o recomendar.

$\S 1^{\circ} \mathrm{A}$ escola poderá reclassificar os alunos, inclusive quando se tratar de transferências entre estabelecimentos situados no País e no exterior, tendo como base as normas curriculares gerais.

$\S 2^{\circ} \mathrm{O}$ calendário escolar deverá adequar-se às peculiaridades locais, inclusive climáticas e econômicas, a critério do respectivo sistema de ensino, sem com isso reduzir o número de horas letivas previsto nesta Lei (BRASIL, 1996). 


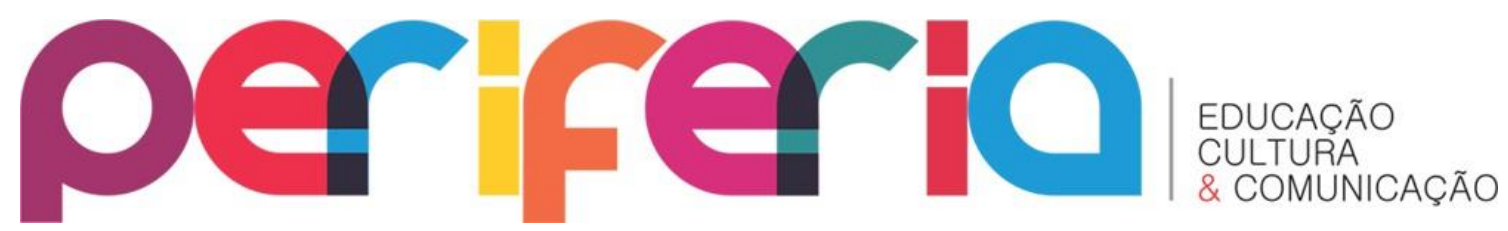

E, ainda, ao tratar especificamente da "educação rural" prevê, no artigo 28:

Art. 28. Na oferta de educação básica para a população rural, os sistemas de ensino promoverão as adaptações necessárias à sua adequação às peculiaridades da vida rural e de cada região, especialmente:

I - conteúdos curriculares e metodologias apropriadas às reais necessidades e interesses dos alunos da zona rural;

II - organização escolar própria, incluindo adequação do calendário escolar às fases do ciclo agrícola e às condições climáticas;

III - adequação à natureza do trabalho na zona rural.

Autoriza, assim, adaptações necessárias às peculiaridades da vida rural de cada região, o que é importante considerando que o Brasil tem diversos cenários e configurações rurais, desde população ribeirinha, quilombolas até pequenos agricultores familiares.

Uma importante alteração legislativa ocorreu na LDB no ano de 2014, por meio da Lei n. 12.960, que acrescentou o parágrafo único ao artigo 28 exigindo para o fechamento das escolas do campo, indígenas e quilombolas a manifestação do órgão normativo do respectivo sistema de ensino, e a análise de diagnóstico do impacto da ação bem como a manifestação da comunidade escolar:

Parágrafo único. O fechamento de escolas do campo, indígenas e quilombolas será precedido de manifestação do órgão normativo do respectivo sistema de ensino, que considerará a justificativa apresentada pela Secretaria de Educação, a análise do diagnóstico do impacto da ação e a manifestação da comunidade escolar (BRASIL, 2014).

Essa necessidade de manifestação da comunidade escolar, bem como análise do impacto do fechamento das escolas adveio da urgência de controlar 


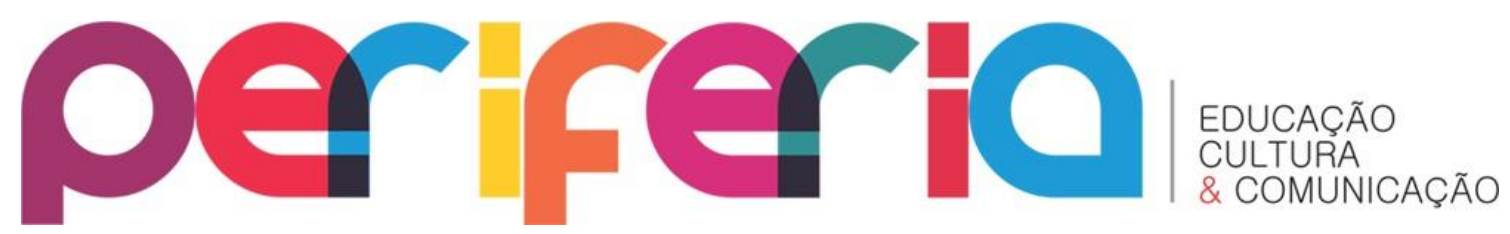

ISSN:1984-9540

DOI: $10.12957 /$ periferia.2021.55833

o fechamento das escolas no campo, que em decorrência do processo de nucleação e municipalização do ensino, houve um enorme número de escolas no campo fechadas, sem a escuta das comunidades e sem análise do impacto do fechamento, obrigando crianças e adolescentes a fazerem deslocamentos por muitos quilômetros para chegar à escola. Taffarel e Munarim (2015) apontam, que na primeira década dos anos 2000 as escolas do campo foram reduzidas em $31,46 \%$.

A lei foi conquistada pelo Movimento Nacional de Educação do Campo, com o mote "Fechar Escola é Crime" (TAFFAREL; MUNARIM, 2015), e é imprescindível que seja conhecida por educadores e pela população do campo.

\section{Escolas Multisseriadas}

A multisseriação ou reunião de estudantes de séries diferentes, da educação fundamental ou da educação infantil em uma mesma sala é uma realidade do sistema escolar brasileiro, particularmente na educação no campo.

Não há legislação federal específica que regule os critérios para distribuição de estudantes, número de professores e limite de séries na mesma sala de aula.

Mas, quanto à da educação no campo, a Resolução Conselho Nacional de Educação, Câmara de Educação Básica (CNE/CEB) número 2 de 2008 prevê a possibilidade multisseriação a fim de garantir que os estudantes tenham acesso à escola nas próprias comunidades em que residem, evitando o deslocamento e o fechamento de escolas e cumprindo o direito que está assegurado pelo Estatuto da Criança e do Adolescente:

Art. 100 planejamento da Educação do Campo, oferecida em escolas da comunidade, multisseriadas ou não, e quando a nucleação rural for considerada, para os anos do Ensino Fundamental ou para o Ensino Médio ou Educação Profissional Técnica de nível médio integrada com o Ensino Médio, considerará sempre as distâncias de deslocamento, as condições de estradas e vias, o estado de conservação dos veículos utilizados e sua idade de uso, a melhor localização e 


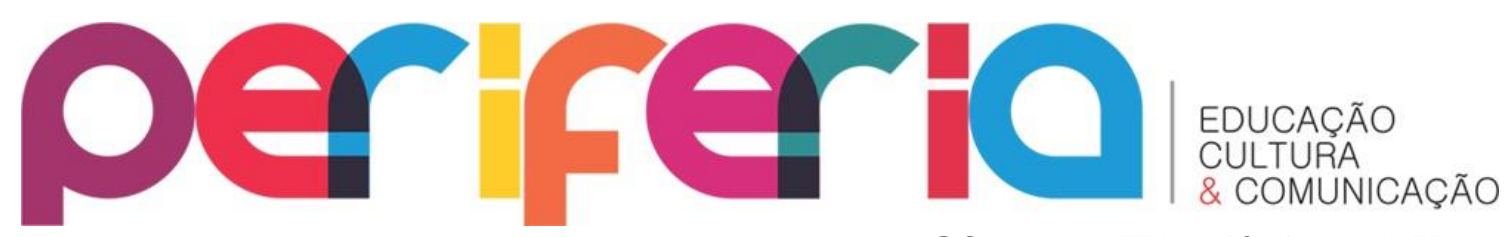

DOI: $10.12957 /$ periferia.2021.55833 as melhores possibilidades de trabalho pedagógico com padrão de qualidade (BRASIL, 2008).

Para garantir o padrão de qualidade definido em âmbito nacional é necessária a formação pedagógica inicial e continuada dos professores, bem como instalações físicas e equipamentos adequados, materiais didáticos apropriados e supervisão pedagógica permanente (BRASIL, 2008, art. 10, $\S 2^{\circ}$ ).

Um dos critérios estabelecidos na Resolução, para garantir a qualidade é a vedação da reunião de estudantes da educação infantil e fundamental na mesma sala:

Art. $3^{\circ}$ A educação infantil e os anos iniciais do Ensino Fundamental serão oferecidos nas próprias comunidades rurais, evitando-se os processos de nucleação de escolas e de deslocamento das crianças.

$\S 1^{\circ}[.$.

$\S$ Em nenhuma hipótese serão agrupadas em uma mesma turma crianças de Educação Infantil com crianças do Ensino Fundamental (BRASIL, 2008).

A necessidade da formação pedagógica para os professores que atuarão na educação no campo ocorre porque nos cursos regulares não há preparação para o trabalho em classes multisseriadas, e ainda está em desenvolvimento a pesquisa acadêmica sobre o assunto, a fim de contribuir com respostas adequadas a este trabalho pedagógico.

É um grande desafio para os educadores que atuam nas escolas multisseriadas porque não está previamente estabelecido como será a organização do espaço e tempo escolar, se haverá divisão das salas por "séries" ou se haverá divisão do tempo. E ainda, qual o limite de estudantes por sala e qual o limite de séries atendidas, dentro do ensino fundamental, por exemplo. $\mathrm{E}$, na maioria das hipóteses tratam-se de escolas unidocentes, ou seja, o professor atuará sozinho em todas as séries que atender.

D’Agostini, Taffarel e Santos Júnior (2012, p. 313) apontam que há muito preconceito quanto às escolas multisseriadas: 


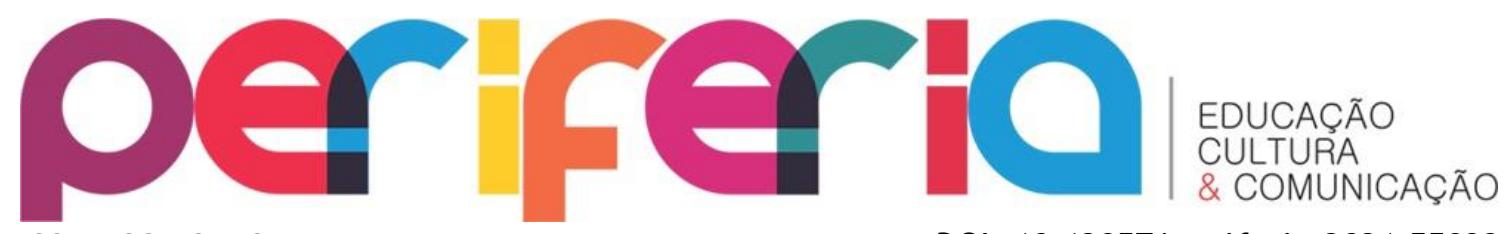

ISSN:1984-9540

DOI: $10.12957 /$ periferia.2021.55833

[...] há muito preconceito e desqualificação das escolas multisseriadas, porém elas são uma forma possível e necessária de organização escolar no campo e podem ser referência de qualidade de ensino se organizadas por ciclos e por princípios multidisciplinares. Isso porque toda criança tem direito a estudar próximo à sua casa e aos seus familiares, o transporte escolar é demasiado perigoso para crianças pequenas, e o cansaço causado pelo mesmo é um agravante para a aprendizagem.

A visão negativa a respeito das escolas multisseriadas também é apontada por Nunes e Bezerra (2018, p. 410/411):

\begin{abstract}
Por ser uma escola que trabalha com predomínio de um único professor em várias séries e níveis de ensino no mesmo espaço, ela é tratada como um mal necessário, causando tensões entre os educadores, pesquisadores e movimentos sociais por vinculála ao atraso e má qualidade do ensino. Por outro lado, deve-se considerar que estas escolas estão se reinventando através de pesquisas e produções teóricas que contribuem para reverter este quadro perverso que, por sua vez, a torna negativa na visão dos que nela trabalham e estudam.
\end{abstract}

$\mathrm{E}$, o preconceito e o desconhecimento a respeito da educação no campo e das escolas multisseriadas faz com que muitas comunidades rurais ou do campo não as defendam, contribuindo para uma cultura de fechamento de escolas e de transporte dos estudantes para a cidade, ou outro local mais distante na zona rural. E, o fechamento de escolas é um prejuízo não só para os estudantes do ensino infantil e fundamental, mas também para a comunidade, que perde o local que muitas vezes era a única presença do Poder Público naquela comunidade ou bairro.

\title{
5. As Escolas com Classes Multisseriadas como possibilidade de concretização do direito à educação da população do campo.
}

Como já afirmado, há um senso comum de que a organização do ensino em salas multisseriadas comprometeriam a qualidade da educação e que a 


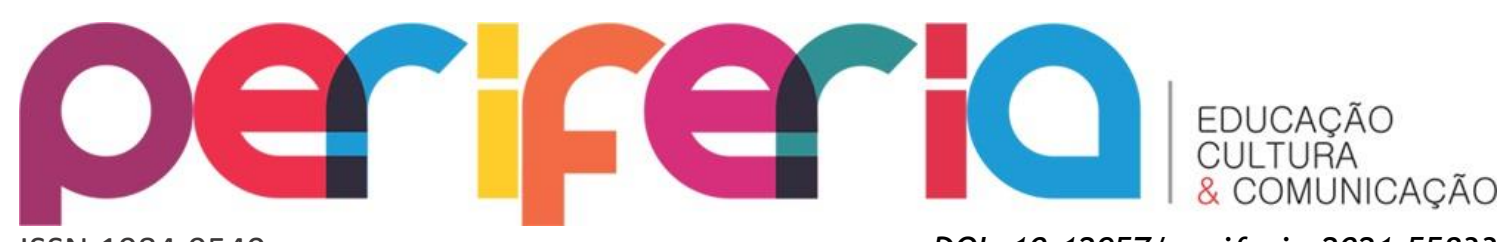

ISSN:1984-9540

DOI: $10.12957 /$ periferia.2021.55833

melhor saída nessas situações, seria o fechamento da escola e o encaminhamento do estudante para outra escola mais distante, para a qual os estudantes dependeriam de transporte.

A título de exemplo, a atuação do Ministério Público de alguns estados brasileiros, no sentido de recomendar o fechamento de tais salas, com o transporte das crianças, exatamente pelo entendimento de que a multisseriação violaria o direito à educação desses estudantes.

Não há como analisar com detalhes tais pedidos porque não se teve acesso aos processos, mas somente às publicações eletrônicas disponíveis na rede mundial de computadores, que informam que o Ministério Público de Santa Catarina obteve liminar para proibir salas multisseriadas em Romelândia (SC) (CNPG, 2013), o Ministério Público Estadual, em Ivinhema (MS) recomendou à Secretaria da Educação que deixe de utilizar a multisseriação (IRREGULARIDADES, 2019) e o Ministério Público do Ceará pleiteou a proibição de escolas multisseriadas no município de Banabuiú (CE) (MPCE, 2018).

Apesar de não se ter acesso ao conteúdo dos processos é certo que as notícias informam que na atuação como instituição que tem como uma das funções defender os direitos das crianças e adolescentes se buscou evitar ou proibir a multisseriação, o que implica, consequentemente, no fechamento de escolas e o transporte dos estudantes.

Hage (2014) explica que as escolas multisseriadas, normalmente se constituem:

[...] na única alternativa para os sujeitos estudarem nas comunidades rurais em que vivem, encontrando-se expostos a um conjunto de situações que não favorecem o sucesso e continuidade dos estudos, evidenciando, inclusive, 0 descumprimento da legislação vigente, que estabelece parâmetros de qualidade a serem alcançados na Educação Básica nas escolas do campo (HAGE, 2014, p. 1173).

Assim, concretizar ou realizar o direito à educação no campo para crianças e adolescentes não é tarefa simples e que pode ser realizada sem a observância das peculiaridades próprias da população do campo, que também 


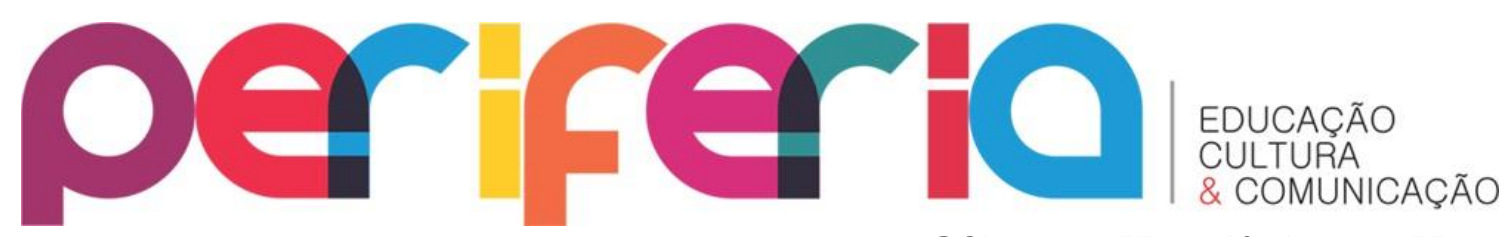

ISSN:1984-9540

DOI: $10.12957 /$ periferia.2021.55833

tem direito que a escola permaneça presente em local de moradia, no local mais próximo de onde reside.

Para Gentili (2009), a realização do direito à educação sofre a interferência de três dinâmicas: a pobreza e a desigualdade estruturais; a segmentação e a diferenciação dos sistemas nacionais de educação e atribuir ao direito à educação o sentido de instrumento para acesso ao mercado de trabalho, em uma cultura política marcada pelo desprezo aos direitos humanos.

E, a população do campo sempre esteve dentre a população mais pobre e que tem menos oferta de educação de qualidade, como sempre foi denunciado pelo movimento da educação no campo.

\begin{abstract}
Historicamente, negou-se aos pobres o direito à educação impedindo seu acesso à escola. Hoje, esse direito é negado quando não lhes é oferecida outra alternativa, a não ser a de permanecer em um sistema educacional que não garante nem cria condições para o acesso efetivo a uma educação de qualidade, quando se limitam as condições efetivas de exercício desse direito pela manutenção das condições de exclusão e desigualdade que se transferiram para o interior do próprio sistema escolar (GENTILI, 2009, p. 1062)
\end{abstract}

A realização do direito à educação do campo não pode ser feita com o fechamento de escolas e salas multisseriadas, com o transporte das crianças, que na maioria das vezes ocorre por estradas mal conversadas, por longos períodos de tempo, causando cansaço e indisposição às crianças, o que afeta diretamente na qualidade do ensino. A falta de qualidade na educação não pode ser atribuída somente à multisseriação.

Há parâmetros que devem ser observados para assegurar a qualidade do ensino nas classes multisseriadas, como a necessária formação pedagógica inicial e continuada dos professores, instalações físicas e equipamentos adequados, materiais didáticos apropriados e supervisão pedagógica permanente e com isto, garantir que haja bom aproveitamento pedagógico.

O fechamento de escolas do campo e a negação da possibilidade de que a multisseriação possa oferecer educação de qualidade às crianças da educação infantil e fundamental é a própria negação do direito à educação, com a 


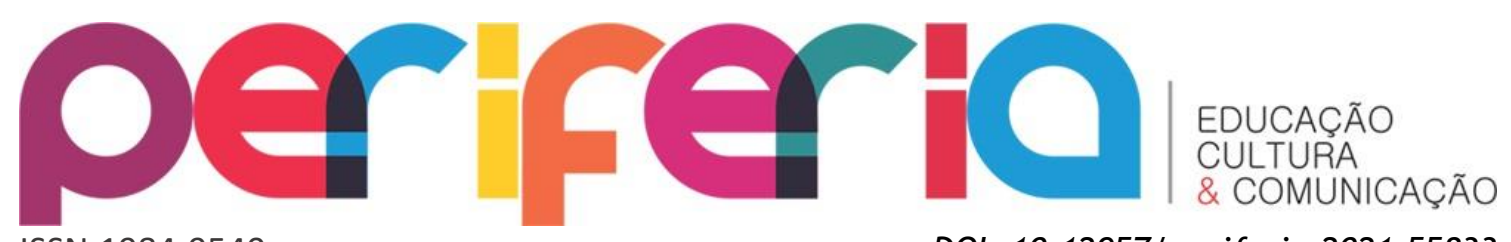

ISSN:1984-9540

DOI: 10.12957/periferia.2021.55833

persistência de um sistema de desigualdade educacional a que a sociedade brasileira está submetida.

Como explica Pablo Gentili, se hoje existem mais possibilidades de acesso à escola há outras formas de exclusão educacional e negação de oportunidades escolares:

Hoje existem mais oportunidades de acesso à escola do que 60 anos atrás, quando foi proclamada a Declaração Universal de Direitos Humanos, mas também se tornaram complexas e difusas as formas de exclusão educacional e a negação das oportunidades escolares daqueles que, estando dentro do sistema, continuam com seu direito à educação negado (2009, p. 1069).

Assim, o grande desafio aos educadores, gestores e movimentos sociais que defendem a educação no campo é para que ela ocorra no próprio local em que as famílias dos estudantes residem e assegurar a qualidade da educação em escolas unidocentes e com salas multisseriadas, para que tenham estrutura adequada e docentes preparados.

$E$, antes que se critique a qualidade das escolas multisseriadas, que implicaria no fechamento dessas escolas, é importante ressaltar que elas somente sobrevivem porque atendem crianças em salas multisseriadas com um único professor. Assim, é preciso refletir sobre possibilidades de concretizar o direito das crianças à educação, ou seja, ao direito de ter acesso conhecimento historicamente produzido pela humanidade nas condições possíveis, entendendo a sala multisseriada como uma opção pedagógica.

Para isso, primeiro, é importante que se cumpra a legislação quanto à infraestrutura das escolas e qualificação dos docentes e suas condições de trabalho. E, também que as secretarias de educação deem apoio e façam acompanhamento de tais escolas, que geograficamente estão distantes e isoladas das demais escolas da rede.

Assim, a melhora da qualidade das escolas multisseriadas não é simplesmente torna-las seriadas da mesma forma que ocorre com as escolas urbanas. Hage aponta que é o "modelo seriado urbano de ensino" que impede a melhora de qualidade nas escolas/classes mutisseriadas: 


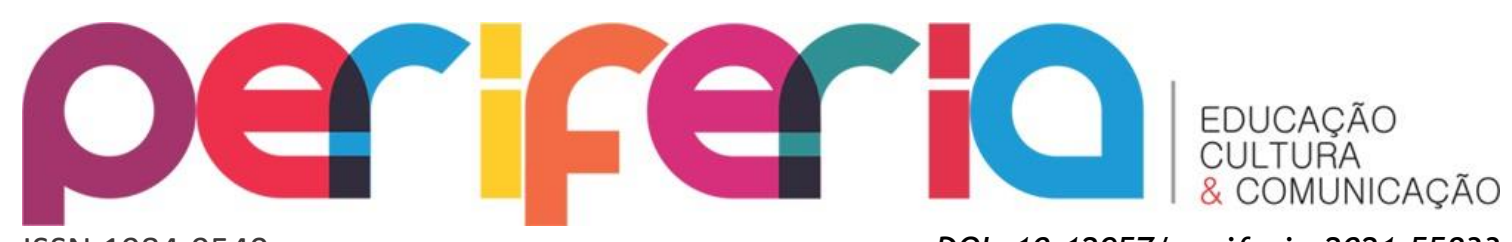

Em nossos estudos constatamos que é justamente a presença do modelo seriado urbano de ensino nas escolas ou turmas multisseriadas que impede que os professores compreendam sua turma como um único coletivo, com suas diferenças e peculiaridades próprias, pressionando-os para organizarem 0 trabalho pedagógico de forma fragmentada, levando-os a desenvolver atividades de planejamento, curricular e de avaliação isolados para cada uma das séries, de forma a atender aos requisitos necessários à sua implementação (HAGE, 2014, p. 1175).

Deve ser assegurada educação pública de qualidade até nos locais mais longínquos em que viva uma criança, e há necessidade de se cumprir o que já está garantido legalmente para assegurar condições de qualidade e preparar os educadores, sistemas de ensino e a própria comunidade para que tais escolas possam ter capacidade de assegurar o direito à escolarização de crianças que vivem no campo.

\section{Considerações Finais}

Concretizar o direito à educação da população do campo, ou ainda, assegurar que toda a população tenha acesso ao conhecimento historicamente sistematizado pela humanidade, é imprescindível para que todos possam exercer outros direitos e ter condições de vida com dignidade.

Os direitos dependem, para sua concretização, que grupos ou indivíduos os exijam e, o primeiro passo, para que possam ser exigidos, é que se tenha conhecimento de sua existência e amplitude, sob pena de o direito ser somente uma previsão abstrata.

A educação no campo é um direito que está em construção, sendo alvo de disputas e também preconceito e desconhecimento e pode-se se afirmar que ainda está a ser conquistado pela classe trabalhadora do campo, que historicamente esteve em condição de maior vulnerabilidade social que a população das cidades. 


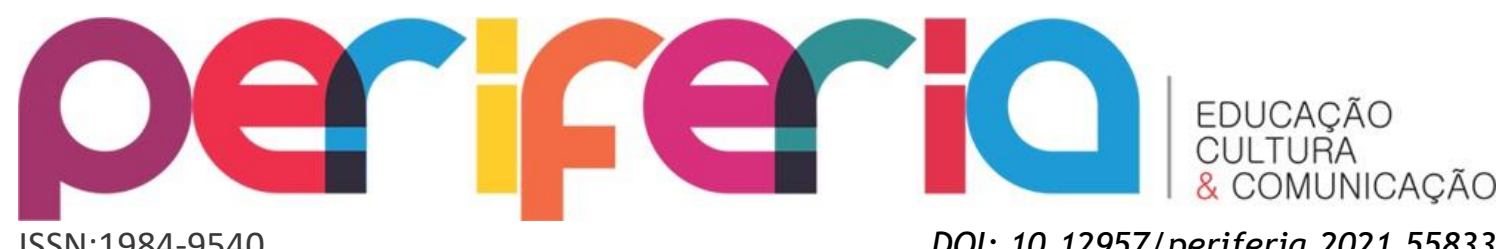

ISSN:1984-9540

DOI: 10.12957/periferia.2021.55833

A possibilidade de organização da educação infantil e fundamental em salas multisseriadas não pode ser vista a partir do senso comum, ou com preconceitos, mas sim, como uma forma de proporcionar educação de qualidade para crianças no seu local de moradia, desde que atendidos os requisitos de estrutura adequada, preparação e supervisão docente. Ou seja, se atendidos estes requisitos legais para que as salas multisseriadas tenham qualidade, não é o simples fato de não serem seriadas que ferirá o direito à educação das crianças do campo.

Para concretizar o direito à educação do campo, deve-se observar suas peculiaridades e necessidades próprias, garantindo a igualdade de condições de acesso e permanência na escola, com a manutenção da escola próxima à criança.

E, se já existiram avanços na concretização do direito à educação, e reconhece-se que sim, ainda há muito a ser concretizado e garantido, razão pela qual é necessário que os educadores e educandos possam exercer sua cidadania e fazer cumprir o que já está legislado, bem como seguir lutando pela educação pública, gratuita, de qualidade e socialmente referenciada.

\section{REFERÊNCIAS}

BRASIL. Constituição da República Federativa do Brasil de 1988. Disponível em:

http://www.planalto.gov.br/ccivil_03/constituicao/constituicaocompilado.ht m. Acesso em 01 nov. 2020.

BRASIL. Lei 8.069, de 13 de julho de 1990. Dispõe sobre o Estatuto da Criança e do Adolescente e dá outras providências. Disponível em:

http://www.planalto.gov.br/ccivil_03/leis/l8069.htm. Aceso em 01 nov. 2020.

BRASIL, Lei 9.394 de 20 de dezembro de 1996. Estabelece as Diretrizes e Bases da Educação Nacional. Disponível em:

http://www.planalto.gov.br/ccivil_03/leis/19394.htm. Acesso em 01 nov. 2020.

BRASIL, Conselho Nacional de Educação. Câmara de Educação Básica. Resolução n. 2/2008. Estabelece diretrizes complementares, normas e princípios para o desenvolvimento de políticas públicas de atendimento da Educação Básica do Campo. Brasília, 2008. 


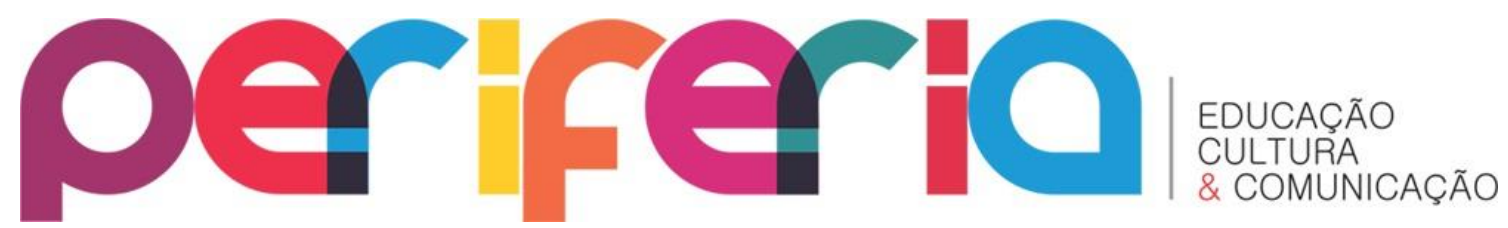

ISSN:1984-9540

DOI: $10.12957 /$ periferia.2021.55833

BRASIL, Decreto n. 7.352, de 4 de novembro de 2010. Dispõe sobre a política de educação do campo e o Programa Nacional de Educação na Reforma Agrária -PRONERA. Brasília, 2010.

BRASIL. Lei n. 12.960 de 27 de março de 2014. Altera a Lei 9.394, de 20 de dezembro de 1996, que estabelece as diretrizes e bases da educação nacional, para fazer constar a exigência de manifestação de órgão normativo do sistema de ensino para o fechamento de escolas do campo, indígenas e quilombolas. Disponível em: http://www.planalto.gov.br/ccivil_03/_Ato20112014/2014/Lei/L12960.htm\#art1. Acesso em 10 ago. 2020

BEZERRA NETO, Luiz. SANTOS, Flávio Reis. Educação no Campo: história, desafios e perspectivas atuais. In: BASSO, Jaqueline Daniela. SANTOS NETO, José Leite. BEZERRA, Maria Cristina do Santos. Pedagogia Histórico-Crítica e educação no campo: história, desafios e perspectivas atuais. São Carlos: Pedro \& João Editores, 2016.

CNPG - Conselho Nacional Procuradores Gerais. Proibidas salas multisseriadas em escola estadual de Romelândia. 01-03-2013. Disponível em:

https://www.cnpg.org.br/index.php/noticias-outros-mps/39-mpsc/2070-

santa-catarina-proibidas-salas-multisseriadas-em-escola-estadual-deromelandia\%20(2013). Acesso em 01 nov. 2020.

CURY, Carlos Roberto Jamil. Direito à educação: direito à igualdade, direito à diferença. Cadernos de Pesquisa, São Paulo, n. 116, p. 245-262, jul. 2002.

D’AGOSTINI, Adriana. TAFFAREL, Celi Zulke SANTOS JUNIOR, Cláudio de Lira. Escola Ativa. In: CALDART, Roseli Salete et al. Dicionário da Educação do Campo. $2^{\mathrm{a}}$ edição. Rio de Janeiro, São Paulo: Escola Politécnica de Saúde Joaquim Venâncio, Expressão Popular, 2012.

GENTILI, Pablo. O Direito à Educação e as Dinâmicas de Exclusão na América Latina. Educação e Sociedade, Campinas, vol. 30, n. 109, p. 1059-1079, set/dez. 2009.

HAGE, Salomão Antonio Mufarrej. Transgressão Do Paradigma Da (Multi)Seriação Como Referência Para A Construção Da Escola Pública Do Campo. Educação e Sociedade, Campinas, v. 35, nº 129, p. 1165-1182, out.dez., 2014.

IRREGULARIDADES em salas multisseriadas motiva recomendação do MPE, em Ivinhema. Jornal da Nova. 06-09-2019. Disponível em https://jornaldanova.com.br/noticia/397226/irregularidades-em-salasmultisseriadas-motiva-recomendacao-do-mpe-em-ivinhema. Acesso em 01 nov. 2020

MAIA, Maria Cláudia. A proteção constitucional do direito à educação: os instrumentos jurídicos para sua efetivação. São Paulo: Porto de Ideias, 2011. 


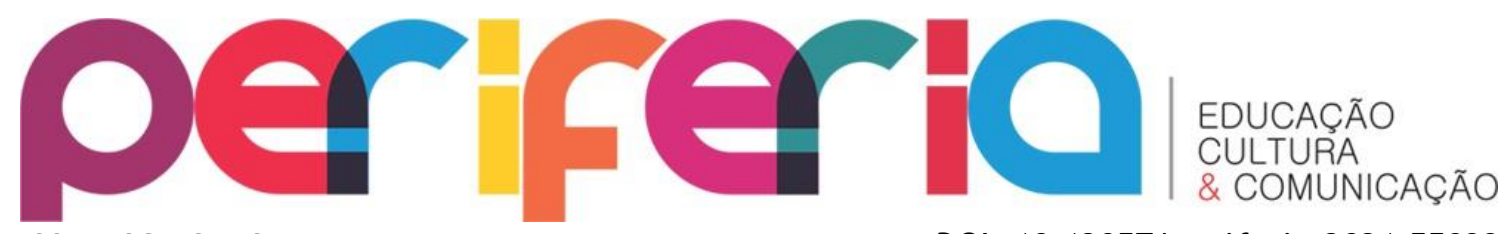

ISSN:1984-9540

DOI: 10.12957/periferia.2021.55833

MAIA, Maria Cláudia Zaratini. Direito é luta: o legado do Pronera para uma educação socialmente referenciada. Tese (Doutorado em Educação).

Departamento de Educação da Universidade Federal de São Carlos - UFSCar. São Carlos-SP, 2019.

MOLINA, Mônica Castagna. Reflexões sobre o significado do protagonismo dos Movimentos Sociais na construção de Políticas Públicas de Educação do Campo In: MOLINA, Mônica Castagna (Org) Educação do Campo e Pesquisa II: questões para reflexão. Brasília: MDA/MEC, 2010.

MPCE - Ministério Público do Ceará. MPCE requer proibição de classes multisseriadas em escolas municipais de Banabuiú. 27-06.2018. Disponível em: http://www.mpce.mp.br/2018/06/27/mpce-requer-proibicao-de-classesmultisseriadas-em-escolas-municipais-de-banabuiu/ Acesso em 01 nov. 2020.

NUNES, Klívia de Cássia Silva; BEZERRA, Maria Cristina dos Santos. Escolas Multisseriadas e Pedagogia Histórico-Crítica: início de uma reflexão. Educação: Teoria e Prática. Rio Claro, SP Vol. 28, n.58 p. 408-425 MaioAgosto. 2018. ISSN 1981-8106

TAFFAREL, Celi Nelza Zulke.; MUNARIM, Antonio. Pátria educadora e fechamento de escolas do campo: o crime continua. Revista Pedagógica, Chapecó, v. 17, n. 35, p. 41-51, maio/ago. 2015

TAFFAREL, Celi Nelza Zulke. SANTOS JUNIOR, Cláudio de Lira. Pedagogia Histórico-Crítica e Formação de Docentes para a Escola do Campo. Educação \& Realidade, Porto Alegre, v. 41, n. 2, p. 429-452, abr./jun. 2016

TAGLIAVINI, João Virgílio.; TAGLIAVINI, Maria Cristina Braga; MAIA, Maria Cláudia. Educação básica obrigatória: a luta pela efetivação dos direitos já garantidos. In: CONTI, Celso Aparecido; RISCAL, Sandra Aparecida. Política nacional de formação de gestores de educação: parceria entre o governo federal e a UFSCar. São Carlos: EdUFSCar, 2015. 